\title{
Detemir as a once-daily basal insulin in type 2 diabetes
}

\author{
Scott E Nelson \\ Cleveland Family Medicine, \\ Cleveland, Mississippi, USA
}

Correspondence: Scott E Nelson Cleveland Family Medicine, 907 East Sunflower Road, Ste 104, Cleveland, MS 38732, USA

Tel $+|66272| 1399$

Fax +I 6628461728

Email drscott@clevelandfamilymed.com
This article was published in the following Dove Press journal:

Clinical Pharmacology:Advances and Applications

17 August 2011

Number of times this article has been viewed

Background: Insulin detemir, a long-acting basal insulin analog, is labeled for once-daily or twice-daily dosing in patients with type 1 (T1DM) or type 2 (T2DM) diabetes mellitus. Protocols for some earlier clinical studies of detemir evaluated twice-daily dosing, which may have generated the misperception that detemir should be prescribed twice daily for most patients. This review examines pharmacokinetic and pharmacodynamic (PK/PD), observational, and controlled studies that have evaluated once-daily and twice-daily detemir in patients with T2DM to determine the efficacy and safety of once-daily dosing.

Methods: PubMed was searched using the keywords "detemir," "once daily," "twice daily," and "type 2 diabetes" with the limits of clinical trial, human, and English.

Results: Detemir has a relatively flat time-action profile and duration of action of up to 24 hours for patients with T2DM. Once-daily dosing is the most commonly used detemir regimen reported in observational studies, and controlled clinical studies indicate that once-daily dosing controls glycosylated hemoglobin when detemir is administered alone or in combination with a prandial insulin or oral antidiabetes drugs. In comparative clinical trials, detemir had a similar time-action profile and duration of action to another long-acting insulin analog, glargine, with less within-subject variability. Once-daily detemir was associated with no weight gain or less weight gain than comparator regimens. For patients who had not achieved glycemic control with a basal dose of once-daily detemir, adding a prandial insulin provided better glycemic control, less postprandial hypoglycemia, and a lower total daily dose of detemir than twice-daily detemir. Involvement of a multidisciplinary team and the use of a holistic approach for the treatment of T2DM patients are recommended to achieve and maintain the best patient outcomes.

Conclusion: Results from PK/PD, observational, and controlled clinical studies support a once-daily detemir regimen alone or in combination with a prandial insulin or oral antidiabetes drugs.

Keywords: basal insulin, detemir, type 2 diabetes mellitus, pharmacokinetics, pharmacodynamics

\section{Introduction}

The joint American Diabetes Association/European Association for the Study of Diabetes (ADA/EASD) 2009 consensus algorithm for initiation and adjustment of therapy for patients with type 2 diabetes mellitus (T2DM) recommends as tier 1 those treatments that have been shown to be well validated and that represent the most well-established and effective strategies. ${ }^{1}$ Tier $1 /$ step 1 interventions recommended by ADA/EASD are lifestyle changes (to decrease weight and increase activity) and metformin therapy. If these interventions fail to achieve or sustain glycemic goals within 2-3 months, the recommended tier 1/step 2 intervention is to initiate treatment with insulin (intermediate or long-acting basal insulin) or a sulfonylurea. Adding or using 
other antidiabetes therapies is considered a tier 2 intervention (ie, a less well-validated treatment strategy). The ADA/ EASD algorithm recommends the rapid addition of medications and transition to new regimens when target glycemic goals are not achieved or sustained, including the early addition of insulin therapy. ${ }^{1}$

The ADA 2011 "Standards of medical care" support using the ADA/EASD algorithm but prioritize treatments that achieve and maintain glycemic targets safely over the use of specific drug therapies in the exact algorithm sequence. ${ }^{2}$ Basal insulin therapy is regarded as the foundation insulin for building glycemic control, especially as a once-daily regimen. Currently available basal insulin therapies include intermediate-acting neutral protamine Hagedorn (NPH) and the long-acting basal insulin analogs glargine and detemir. $\mathrm{NPH}$ insulin is a crystalline suspension of human insulin with protamine and zinc that provides an intermediate-acting insulin with a slower onset of action and a longer duration of activity than regular human insulin. ${ }^{3} \mathrm{NPH}$ insulin is used for the treatment of patients with T2DM or type 1 diabetes mellitus (T1DM). It has a peak of activity in 5-10 hours, resulting in a higher incidence of postprandial hypoglycemia than the long-acting insulin analogs, which display no peak effect. ${ }^{4}$ NPH insulin has an effective duration of 12-18 hours, and thus is administered twice daily for most patients. Similar to all insulin formulations, NPH insulin's duration of action is dependent on dose, site of injection, blood supply, temperature, and physical activity. ${ }^{3}$ The addition of insulin to the treatment regimen of patients with T2DM is considered a step 2 option; ${ }^{1}$ however, because of the higher incidence of postprandial hypoglycemia and the need for twice-daily dosing, NPH is usually considered after longer-acting insulins.

Long-acting insulins such as glargine and detemir are effective for basal control of glucose, but do not target glucose fluctuations that occur after a meal. ${ }^{5}$ Rapid-acting insulins are more effective at controlling postprandial glucose concentrations. This is the rationale for adding rapid-acting bolus insulin before meals in patients receiving long-acting basal insulin who are above target postprandial glucose levels.

Glargine is a recombinant long-acting insulin analog that is US Food and Drug Administration (FDA) approved for patients with T2DM and T1DM. ${ }^{6}$ Molecular changes allow glargine to form microprecipitates in the neutral $\mathrm{pH}$ of subcutaneous tissue, and glargine is slowly released from these precipitates over the dosing interval. In patients with T2DM, subcutaneous absorption of insulin glargine was two to three times slower than NPH insulin as determined by disappearance of radio-labeled glargine from the injection site. ${ }^{7}$ For insulin glargine vs NPH insulin, the median time for $25 \%$ of the radioactivity to disappear was $15 \mathrm{vs} 6.5$ hours and for $75 \%$ to disappear was 42.4 vs 26.6 hours, respectively. The duration of action of subcutaneously administered glargine is up to 24 hours and it is administered once daily in most patients. ${ }^{6}$

Twice-daily dosing of glargine has been evaluated in patients with T1DM. ${ }^{8-10}$ According to a review by Devries et al glargine and detemir administered once daily both display a dose-dependent waning of glycemic effect, which necessitates twice-daily administration in some patients with T1DM. ${ }^{11}$ The rationale for this is that long-acting insulins administered once daily provide glycemic control for basal glucose production. All insulins display a dose-dependent effect and a relative dose-dependent duration of action. If the basal insulin dose is split, the total twice-daily dose of insulin is likely to be higher than the once-daily dose because the long-acting insulin will provide coverage for both basal and predinner glucose concentrations. To avoid twice-daily dosing of a basal insulin, a rapid-acting insulin should be added to the insulin regimen to cover prandial glucose concentrations. ${ }^{11}$ Although only reported for glargine in T1DM patients, a waning of glycemic effect requiring twice-daily administration likely occurs in patients with T2DM as well. ${ }^{11}$

Detemir is a biosynthetic long-acting insulin analog that is FDA-approved for patients with T2DM or T1DM. It is structurally modified to self-associate and bind reversibly to albumin and is soluble at a neutral $\mathrm{pH} .{ }^{12,13}$ These characteristics mediate detemir's slow absorption from the subcutaneous administration site and result in a protracted duration of action compared with conventional human insulin formulations. Detemir has a duration of action of up to 24 hours. ${ }^{14}$ It is soluble in subcutaneous tissue, which may be why detemir has reduced inter- and intrapatient variability compared with other agents, since precipitation and dissolution of a precipitate (required for NPH and glargine absorption) are unpredictable processes. ${ }^{15}$ The detemir prescribing information recommends that, for patients with T2DM or T1DM currently receiving only basal insulin, changing the basal insulin to detemir can be done on a unit-to-unit basis. For insulin-naive patients with T2DM who are inadequately controlled on oral antidiabetic drugs, detemir should be started at a dose of $0.1-0.2$ units $/ \mathrm{kg}$ once daily in the evening or 10 units once or twice daily, and the dose adjusted to achieve glycemic targets. ${ }^{14}$ 
In early studies of detemir, twice-daily dosing was used for direct comparison of detemir to NPH insulin and to seek an additional indication. Recent clinical studies support oncedaily administration of detemir in combination with other antidiabetes therapies for most patients with T2DM. Despite this and the FDA-approval for once or twice-daily dosing, there are misconceptions that detemir should be administered twice daily for most patients. This review discusses studies that have evaluated twice-daily and once-daily dosing of detemir in patients with T2DM and addresses these misconceptions. To identify studies for this review, a search of PubMed was conducted for publications with the keywords "detemir," "once daily," "twice daily," and "type 2 diabetes" using the limits of clinical trial, human, and English.

\section{Detemir pharmacokinetics and pharmacodynamics (PK/PD) in T2DM patients}

A randomized, double-blind, euglycemic clamp study of 27 overweight men with T2DM was conducted to compare the time-action profiles of detemir and glargine insulins. ${ }^{16}$ Using a continuous glucose monitoring system, both insulins displayed similar flat time-action profiles with no pronounced activity peaks, and a duration of action of up to 24 hours. Maximum glucose infusion rates $\left(\mathrm{GIR}_{\max }\right)$ increased in linear fashion for both insulins. The GIR ${ }_{\max }$ for detemir doses of $0.4,0.8$, and 1.4 units $/ \mathrm{kg}$ were $0.9 \pm 0.6$, $1.5 \pm 0.8$, and $2.4 \pm 1.2 \mathrm{mg} / \mathrm{kg} / \mathrm{min}$, respectively. The GIR ${ }_{\max }$ for glargine doses of $0.4,0.8$, and 1.4 units $/ \mathrm{kg}$ were $0.8 \pm 0.8$, $1.8 \pm 1.6$, and $2.9 \pm 1.8 \mathrm{mg} / \mathrm{kg} / \mathrm{min}$, respectively. Both insulins displayed an increase in peak and total plasma levels with increasing dose. The durations of action of detemir and glargine were similar at comparable doses. In the high-dose (1.4 units $/ \mathrm{kg}$ ) detemir and glargine groups, the duration of action was $22 \pm 2.6$ hours and 24 hours, respectively. With the clinically relevant low and medium doses $(0.4$ and 0.8 units $/ \mathrm{kg}$ ), the durations of action were comparable and estimated to be less than 24 hours for detemir and glargine insulins. Durations of action for detemir and glargine at the 0.4 units $/ \mathrm{kg}$ dose were $12.0 \pm 8.5$ and $10.2 \pm 7.4$ hours, and for the 0.8 units $/ \mathrm{kg}$ dose were $16.8 \pm 6.8$ and $19.4 \pm 6.9$ hours, respectively. In this analysis, duration of action was determined based on the GIR profile. Glucose clamp studies in patients with T2DM may not be effective in accurately detecting the duration of action since the fasting plasma glucose (FPG) level is supported by endogenous insulin secretion. Glucose clamp studies are more useful in determining withinpatient variability. Detemir, an albumin-bound insulin, displayed significantly less within-patient variability than glargine (GIR max $_{\text {ax }}$ [coefficient of variation, CV] $40 \%$ vs $147 \%$ for detemir and glargine, respectively; $P<0.001)$. Betweenpatient variability was similar between groups $\left(\mathrm{GIR}_{\max }[\mathrm{CV}]\right.$ $66 \%$ vs $46 \%$ for detemir and glargine, respectively; $P=$ not significant [NS]). Both insulins displayed an increase in the effect with increasing dose and a duration of action of up to 24 hours.

A more recent randomized, double-blind, crossover study of 29 men and women with T2DM also showed that detemir had a time-action profile, duration of action, and variation in glycemic effect similar to glargine as measured by continuous glucose monitoring. ${ }^{17}$ Patients had similar mean 24-hour blood glucose levels ( $133 \pm 21$ vs $126 \pm 20 \mathrm{mg} / \mathrm{dL}$ detemir vs glargine; $P=0.385$ ) and similar basal blood glucose levels $(105 \pm 23$ vs $98 \pm 19 \mathrm{mg} / \mathrm{dL} ; P=0.204)$. In addition, the mean dose of detemir once daily was similar to the glargine oncedaily dose (26.3 vs 26.6 units/day; $P=0.837$ ). Basal glucose control was achieved in all patients in a mean of 3.8 days for detemir and 3.5 days for glargine $(P=0.360)$.

PK/PD data support the efficacy of once-daily dosing of detemir. Questions regarding the accumulation of detemir, resulting in an increased metabolic effect, have also been addressed. According to Bott et al ${ }^{18}$ glucose clamp data indicate that detemir twice daily reaches steady state after the second injection, with no further increase of the metabolic effect thereafter.

\section{Clinical studies using detemir twice daily in T2DM patients}

Clinical studies have used a protocol of detemir administered only twice daily ${ }^{19}$ or once or twice daily ${ }^{20-23}$ to assess safety and efficacy compared with NPH or glargine insulins.

A randomized, treat-to-target trial was conducted to assess the safety and efficacy of adding basal insulin therapy (with twice-daily detemir or NPH insulin) to suboptimal oral antidiabetes drug therapy. ${ }^{19}$ Insulin-naive patients with T2DM $(n=475)$ had glycosylated hemoglobin $A_{1 c}(A 1 C)$ values decrease by $1.8 \%(8.6 \%$ to $6.8 \%)$ and $1.9 \%(8.5 \%$ to $6.6 \%)$ in the detemir and NPH groups, respectively $(P=\mathrm{NS})$. The risk of any type of hypoglycemic event and nocturnal hypoglycemia was reduced by $47 \%$ and $55 \%$, respectively, with detemir compared with $\mathrm{NPH}$ insulin therapy $(P<0.001$ for both). Mean weight gain was significantly less with detemir $(1.2 \mathrm{~kg})$ than NPH insulin therapy $(2.8 \mathrm{~kg}$; $P<0.001)$. Detemir twice daily showed similar glycemic control with less hypoglycemia and less weight gain compared with NPH twice daily. 
The safety and efficacy of a basal-bolus regimen of detemir (once or twice daily) or NPH in combination with prandial insulin were compared in 505 patients with T2DM. ${ }^{20}$ Following 26 weeks of treatment, significant reductions in A1C from baseline were observed in both groups (detemir $0.2 \% ; P=0.004$ and NPH $0.4 \% ; P<0.001)$. The number of injections of detemir did not significantly change A1C levels $(P=0.50)$. At the end of the treatment period, $39 \%$ and $61 \%$ of patients were receiving detemir once daily and twice daily, respectively; $41 \%$ and $59 \%$ were receiving NPH once daily and twice daily, respectively. Detemir administration was associated with less weight gain than $\mathrm{NPH}$. The mean change in body weight (adjusted for baseline weight and country) was $1.0 \mathrm{~kg}$ for detemir and $1.8 \mathrm{~kg}$ for NPH insulin ( $P=0.017$ between groups). Significantly less within-subject variability in day-to-day fasting selfmonitored blood glucose was reported with detemir than with NPH insulin. The mean self-measured FPG concentrations were $7.5 \mathrm{mmol} / \mathrm{L}(135.0 \mathrm{mg} / \mathrm{dL})$ and $7.6 \mathrm{mmol} / \mathrm{L}$ $(136.8 \mathrm{mg} / \mathrm{dL})$, respectively; and standard deviation (SD) (CV\%) were $1.3(17.6 \%)$ and 1.4 (18.5\%), respectively $(P=0.021) .{ }^{20}$ The reduced variability is likely due to more consistent release of detemir because, unlike NPH insulin, detemir remains in solution in subcutaneous tissue and does not rely on dissolution of the insulin precipitates for absorption. ${ }^{15}$ Less within-subject glycemic variability could reduce the risk of glucose excursions and the lack of a peak effect reduces the likelihood of postprandial hypoglycemic events. ${ }^{15}$

An open-label, treat-to-target trial was conducted to compare detemir once daily or twice daily with glargine $(1: 1: 1)$ in a basal-bolus regimen in 319 patients with T2DM. ${ }^{22}$ Exploratory analyses were conducted on trial completers ( $n=257)$ to compare once-daily detemir to glargine. The mean decrease in $\mathrm{A} 1 \mathrm{C}$ was $1.61 \%$ and $1.79 \%$ in oncedaily detemir and glargine-treated patients, respectively. Overall incidence of hypoglycemia and within-patient variability were similar between groups. The mean weight gain was $3.1 \mathrm{~kg}$ and $4.2 \mathrm{~kg}$ for once-daily detemir completers and glargine-treated completers, respectively. The relative risk (RR) of nocturnal hypoglycemia was similar with once-daily and twice-daily administered detemir and glargine (once-daily RR 0.63 [95\% confidence interval (CI) 0.37-1.06] and twicedaily RR 1.15 [0.68-1.94]). Basal insulin doses were 0.69 and 0.95 units $/ \mathrm{kg}$ daily for patients receiving detemir once daily and twice daily, respectively; the glargine dose was 0.59 units/ $\mathrm{kg}$ daily. The higher basal dose in the detemir group may have been a result of the protocol, which allowed detemir-treated patients to be switched from once to twice-daily dosing based on an elevated predinner glucose measurement. A post hoc analysis revealed that if the glargine cohort had been allowed to follow the same dosing protocol, $83.8 \%$ would have met criteria to switch to twice-daily dosing. The same analysis applied to the detemir group revealed that $82.7 \%$ of patients should have received twice-daily dosing rather than the $57.2 \%$ that actually did receive this regimen. Therefore, adding a second dose of a basal insulin because of an elevated predinner glucose concentration would result in a large number of patients switching to a twice-daily dosing regimen that offers little to no clinical advantage over once-daily dosing.

A randomized, treat-to-target trial was conducted in 582 insulin-naive patients with T2DM administered once or twice-daily detemir or glargine (1:1 detemir to glargine) in combination with oral antidiabetes drugs. ${ }^{21} \mathrm{By}$ the end of the 52-week study, $45 \%(n=104)$ of detemir-treated patients were receiving detemir once daily and 55\% $(n=129)$ twice daily. Glycemic control was similar between groups. The mean $\mathrm{A} 1 \mathrm{C}$ was $7.12 \%$ and $7.06 \%$ for patients receiving oncedaily and twice-daily detemir, respectively, and was $7.12 \%$ for glargine-treated patients ( $P=\mathrm{NS}$ for detemir vs glargine). The mean clinic FPG was $7.27 \mathrm{mmol} / \mathrm{L}(130.86 \mathrm{mg} / \mathrm{dL})$ and $6.73 \mathrm{mmol} / \mathrm{L}(121.14 \mathrm{mg} / \mathrm{dL})$ for patients receiving once-daily and twice-daily detemir, respectively; and $6.98 \mathrm{mmol} / \mathrm{L}(125.64 \mathrm{mg} / \mathrm{dL})$ for glargine-treated patients ( $P=\mathrm{NS}$ for detemir vs glargine). The variation in glycemic control prebreakfast (within-participant SD $1.06 \mathrm{mmol} / \mathrm{L}$ [19.1 mg/dL] vs $1.03 \mathrm{mmol} / \mathrm{L}[18.5 \mathrm{mg} / \mathrm{dL}] ; P=0.45)$ and predinner $(1.60 \mathrm{mmol} / \mathrm{L}[28.8 \mathrm{mg} / \mathrm{dL}]$ vs $1.55 \mathrm{mmol} / \mathrm{L}$ [27.9 mg/dL] ; $P=0.41)$ was similar between detemir and glargine groups, respectively. The mean daily dose of detemir was 0.52 units $/ \mathrm{kg}$ and $1.00 \mathrm{units} / \mathrm{kg}$ for once-daily and twicedaily dosing, respectively; the mean daily dose of glargine was 0.44 units $/ \mathrm{kg}$. Weight gain was significantly lower in patients administered detemir compared with glargine; the mean change in weight for patients who completed the study ( $\mathrm{n}=482$ ) was $3.0 \mathrm{vs} 3.9 \mathrm{~kg}$, respectively $(P=0.01)$. Patients receiving once-daily detemir gained significantly less weight than those receiving twice-daily dosing (mean weight change 2.3 vs $3.7 \mathrm{~kg}$, respectively; $P<0.001$ ).

A randomized, treat-to-target study compared the efficacy and safety of detemir with glargine in a basal-bolus regimen in 385 patients with T2DM. ${ }^{23}$ At 26 weeks, detemir and glargine had similar A1C reductions, and results met the noninferiority criterion (least squares mean [detemirglargine]: 0.207; 95\% CI, 0.0149-0.3995). At 26 weeks, the least squares mean (standard error, \pm SE) A1C values 
were $7.13 \% \pm 0.073 \%$ for detemir and $6.92 \% \pm 0.091 \%$ for glargine-treated patients $(P=0.035)$; the least squares mean FPG concentrations were $7.22 \mathrm{mmol} / \mathrm{L}(129.7 \mathrm{mg} / \mathrm{dL})$ and $7.44 \mathrm{mmol} / \mathrm{L}(134.3 \mathrm{mg} / \mathrm{dL})$, respectively $(P=0.397)$. Significantly less weight gain was observed in detemir than glargine-treated patients $(1.2 \pm 3.96$ vs $2.7 \pm 3.94 \mathrm{~kg}$, respectively; $P=0.001)$. The risk of hypoglycemia was comparable between groups and there was no difference in within-patient variability. Detemir once daily was the regimen used in $87.4 \%$ throughout the study. The mean doses of insulin were similar between groups ( 0.81 and 0.75 units $/ \mathrm{kg}$ for detemir and glargine, respectively; $P=0.1$ ).

Taken together, the results of these studies suggest that, initially, basal insulin (including detemir) may be administered once daily and that the dose should be increased until the desired FPG level has been achieved. ${ }^{24}$ If the desired predinner target blood glucose level cannot be achieved, the total dose of basal insulin may be divided and administered as two separate injections (morning and evening). However, twice-daily dosing of a basal insulin may not provide the needed glycemic and clinical benefits, and the general understanding is that once-daily dosing is preferred by patients and is associated with better medication adherence than more frequent dosing. 5

\section{Optimizing detemir therapy: designs of clinical studies utilizing detemir once daily in T2DM}

More recent studies evaluating detemir in patients with T2DM have tended to use basal-bolus regimens for patients with limited or no $\beta$-cell function and basal-oral therapy for patients initiating insulin. Most of these detemir studies evaluated once-daily dosing. ${ }^{25-29}$ All studies discussed below are randomized controlled studies except for Predictable Results and Experience in Diabetes through Intensification and Control to Target: an International Variability Evaluation (PREDICTIVE), which is an observational study.

Three randomized, controlled studies evaluated the efficacy of once daily. The first, PREDICTIVE BMI, ${ }^{27}$ was a 26-week, randomized, controlled trial of 277 overweight or obese adults with uncontrolled T2DM (A1C 7.5\%-11.0\%, body mass index [BMI] 25-40 kg/m²). Patients received either detemir or NPH insulin in the evening and insulin aspart at main meals and were allowed to continue taking metformin. At 26 weeks, equivalent glycemic control was reported for both treatment groups. The mean $\mathrm{A} 1 \mathrm{C}$ value decreased from $8.9 \%$ to $7.8 \%$ with once-daily detemir and from $8.8 \%$ to $7.8 \%$ with NPH insulin therapy $(P=\mathrm{NS}$ between-treatment difference). The mean FPG concentration decreased to $8.8 \pm 2.7 \mathrm{mmol} / \mathrm{L}(158.7 \pm 48.6 \mathrm{mg} / \mathrm{dL})$ and $8.9 \pm 3.1 \mathrm{mmol} / \mathrm{L}(160.2 \pm 55.8 \mathrm{mg} / \mathrm{dL})$ in the detemir and NPH groups, respectively $(P=$ NS between-treatment difference). However, significantly less weight gain $(0.4 \mathrm{~kg})$ was reported with detemir than with NPH $(1.9 \mathrm{~kg}$; $P<0.0001$ ), and the risk of a hypoglycemic event was significantly lower with detemir compared with NPH (RR 0.62 [all events] and 0.43 [nocturnal]; $P<0.0001$ for both). The authors concluded that once-daily detemir was effective as part of a basal-bolus regimen for patients with T2DM.

In the second study, a randomized, open-label, multicenter trial of 504 patients with poorly controlled T2DM was conducted at 91 centers across Europe and the USA. ${ }^{28}$ Patients were randomized to either once-daily morning detemir, once-daily evening detemir, or once-daily evening NPH (1:1:1) for 20 weeks. Glycemic control was similar among the detemir and NPH groups, with significantly better glycemic control with evening compared with morning detemir administration. The end of study mean A1C values were $7.5 \%, 7.4 \%$, and $7.35 \%$ for morning detemir, evening detemir, and evening NPH, respectively; and the mean FPG was $8.61 \mathrm{mmol} / \mathrm{L}$ (154.98 mg/dL), $7.17 \mathrm{mmol} / \mathrm{L}$ (129.06 mg/dL), and $7.77 \mathrm{mmol} / \mathrm{L}$ (139.86 mg/dL), respectively $(P<0.001$ morning vs evening detemir). Compared with NPH, evening detemir resulted in 53\% $(P=0.019)$ and $65 \%(P=0.031)$ less 24 -hour and nocturnal hypoglycemia, respectively. Evening detemir and NPH insulin led to a weight gain of 0.7 and $1.6 \mathrm{~kg}$, respectively $(P=0.005)$. Results indicate that detemir given once daily improves glycemic control similar to NPH but may be better tolerated at comparable doses.

The third trial, Treat to Target with Once-daily Insulin Therapy: Reduce A1C by Titrating Effectively (TITRATE) ${ }^{29}$ is a 20 -week, randomized, controlled, open-label, multicenter, treat-to-target study. Insulin-naive patients $(n=244)$ with T2DM received once-daily detemir therapy and were randomized to one of two treatment arms, with doses titrated to achieve target FPG concentrations of $70-90 \mathrm{mg} / \mathrm{dL}$ (3.9-5.0 mmol/L) or $80-110 \mathrm{mg} / \mathrm{dL}(4.4-6.1 \mathrm{mmol} / \mathrm{L})$. Once-daily detemir dosing followed the patient self-adjusted algorithm (303 algorithm) described below. The majority of patients in both groups achieved the ADA target A1C of $<7 \%$ by the end of the study $(64.3 \%$ and $54.5 \%$ for the $70-90 \mathrm{mg} / \mathrm{dL}[3.9-5.0 \mathrm{mmol} / \mathrm{L}]$ or $80-110 \mathrm{mg} /$ $\mathrm{dL}$ [4.4-6.1 $\mathrm{mmol} / \mathrm{L}]$ groups, respectively), and overall, low rates of hypoglycemia were reported (7.73 and 5.27 events/patient/year, respectively). Lowering the fasting 
glucose levels using a self-directed titration algorithm with once-daily detemir was associated with low rates of hypoglycemia and increased the likelihood of achieving the target A1C level. By the end of study, the A1C value in the $70-90 \mathrm{mg} / \mathrm{dL}$ arm was $6.77 \%$, which is the lowest end of study $\mathrm{A} 1 \mathrm{C}$ in a treat-to-target trial with any once-daily basal analog therapy.

Recently, the addition of prandial (bolus) insulin and detemir to oral therapy was evaluated. The Treat to Target in Type 2 Diabetes (4-T) study is a 3-year, open-label, multicenter trial of 708 patients randomly assigned to receive biphasic insulin aspart twice daily, prandial insulin aspart three times daily, or basal detemir once daily (or twice, if required), added to suboptimal therapy with metformin and a sulfonylurea. ${ }^{30}$ Most patients required the addition of aspart in the second and third year of study. All patients treated with basal and prandial insulin-based regimens (such as detemir + aspart) achieved better A1C control than those receiving biphasic insulin therapy by the end of study. The median A1C levels $(6.9 \%$; 95\% CI 6.8\%-7.1\%; $P=0.28$ overall comparison) were similar after 1 year of use for all groups and remained stable at the end of the study. Among patients with a baseline $\mathrm{A} 1 \mathrm{C} \leq 8.5 \%$, patients in the biphasic group were less likely to achieve an $\mathrm{A} 1 \mathrm{C} \leq 6.5 \%$ compared with those in the prandial group (odds ratio [OR] $0.48 ; 95 \%$ CI $0.28-0.82 ; P=0.007$ ) or basal group (OR $0.46 ; 95 \%$ CI $0.27-0.78 ; P=0.004$ ). Detemir therapy was associated with fewer hypoglycemic events. Median numbers of hypoglycemic events per patient per year during the study were biphasic group, 3; prandial group, 5.5; and detemir group, 1.7. After 3 years, less weight gain was observed in the basal group $(3.6 \pm 0.5 \mathrm{~kg})$ than in the biphasic $(5.7 \pm 0.5 \mathrm{~kg})$ or prandial $(6.4 \pm 0.5 \mathrm{~kg})$ insulin groups $(P<0.01$ for biphasic vs basal and prandial vs basal groups). More patients in the biphasic insulin group were taking sulfonylurea therapy at the end of the study compared with the other study groups, which may explain the increased weight gain and hypoglycemic events and smaller A1C reduction in the biphasic group. The median daily insulin dose increased during the second and third study years and was similar for patients receiving prandial or basal insulin therapy (105 units/day [95\% CI 91-119] vs 105.5 units/day [95\% CI 90-212], respectively; $P=0.26$ ). After 1 year, about two thirds of patients receiving detemir were maintained with once-daily injections. ${ }^{31}$ Most patients required the addition of prandial insulin by the second and third year of study. ${ }^{30}$ Perhaps if more patients had received basal-bolus therapy during the first year of therapy, more patients could have achieved the A1C target of $\leq 6.5 \%$, fewer patients could have received twice-daily dosing, and the mean total daily detemir dose could have been lower. Overall, study results provide good evidence of the effectiveness and safety of once-daily detemir. In addition, data suggest that starting with a basal insulin instead of a bolus insulin is a better treatment option before intensification to a basal-bolus regimen because, with comparable glycemic control, patients exhibited less weight gain and less hypoglycemia. ${ }^{30}$

PREDICTIVE was a large-scale, multinational, openlabel, prospective, observational study of 19,911 patients with T1DM or T2DM assessing the safety and efficacy of detemir in day-to-day clinical practice. ${ }^{32}$ Subgroup analyses of the European PREDICTIVE cohorts have been released (see Table 1). ${ }^{33-36}$ Overall, study results indicate that oncedaily detemir effectively controls $\mathrm{A} 1 \mathrm{C}$ and is associated with less weight gain than other regimens evaluated.

PREDICTIVE $303^{25}$ was a 26 -week, multicenter, openlabel, randomized study of 5604 patients, which compared glycemic control and safety with detemir therapy using a patient self-adjusted dosing algorithm (303 algorithm group) to standard-of-care physician-driven adjusted dosing (standard-of-care group). Subjects in the 303 algorithm group were instructed to make insulin dose adjustments as follows: mean FPG $<80 \mathrm{mg} / \mathrm{dL}$, reduce detemir dose by $3 \mathrm{U}$; mean FPG between 80 and $110 \mathrm{mg} / \mathrm{dL}$, no change; mean FPG $>110 \mathrm{mg} / \mathrm{dL}$, increase detemir dose by $3 \mathrm{U}$, hence the name 3-0-3. At 26 weeks, $91 \%$ of the patients in the 303 algorithm group and $85 \%$ in the standard-ofcare group remained on once-daily detemir, based on the mean of three consecutive FPG values, which suggests that detemir is effective as a once-daily dosing regimen. In the small subgroup that received twice-daily detemir, glycemic control was found to be not as good as the once-daily group despite the detemir dose for the twice-daily subgroup being approximately two times the dose used in the once-daily subgroup. Mean A1C values decreased by $0.6 \%$ (from $8.5 \%$ to $7.9 \%$ ) for the 303 algorithm group and by $0.5 \%$ (from $8.5 \%$ to $8.0 \%)$ for the standard-of-care group ( $P=0.0106$ between groups). The mean FPG values decreased by $34 \mathrm{mg} / \mathrm{dL}$ (from 175 to $141 \mathrm{mg} / \mathrm{dL}$ ) for the 303 algorithm group and by $22 \mathrm{mg} / \mathrm{dL}$ (from 174 to $152 \mathrm{mg} / \mathrm{dL}$ ) for the standard-of-care group ( $P<0.0001$ between groups). Mean body weight did not change significantly for either group during the study $(+0.1 \mathrm{~kg}$ for the algorithm group and $-0.2 \mathrm{~kg}$ for the standard-of-care group; $P=\mathrm{NS}$ ). By the end of the study, the dose of detemir was greater in the algorithm group ( 0.64 units $/ \mathrm{kg})$ than the standard-of-care group (0.46 units $/ \mathrm{kg})$, suggesting that the algorithm may 
Table I Summary of PREDICTIVE subgroup analyses by country/region for type 2 diabetes patients

\begin{tabular}{|c|c|c|}
\hline Cohort & Patients, duration, and treatment & Results \\
\hline French $^{33}$ & $\begin{array}{l}N=329 \\
52 \text { weeks } \\
\text { Detemir + OAD }(n=263) \\
\text { or detemir + bolus insulin } \\
(n=66)\end{array}$ & 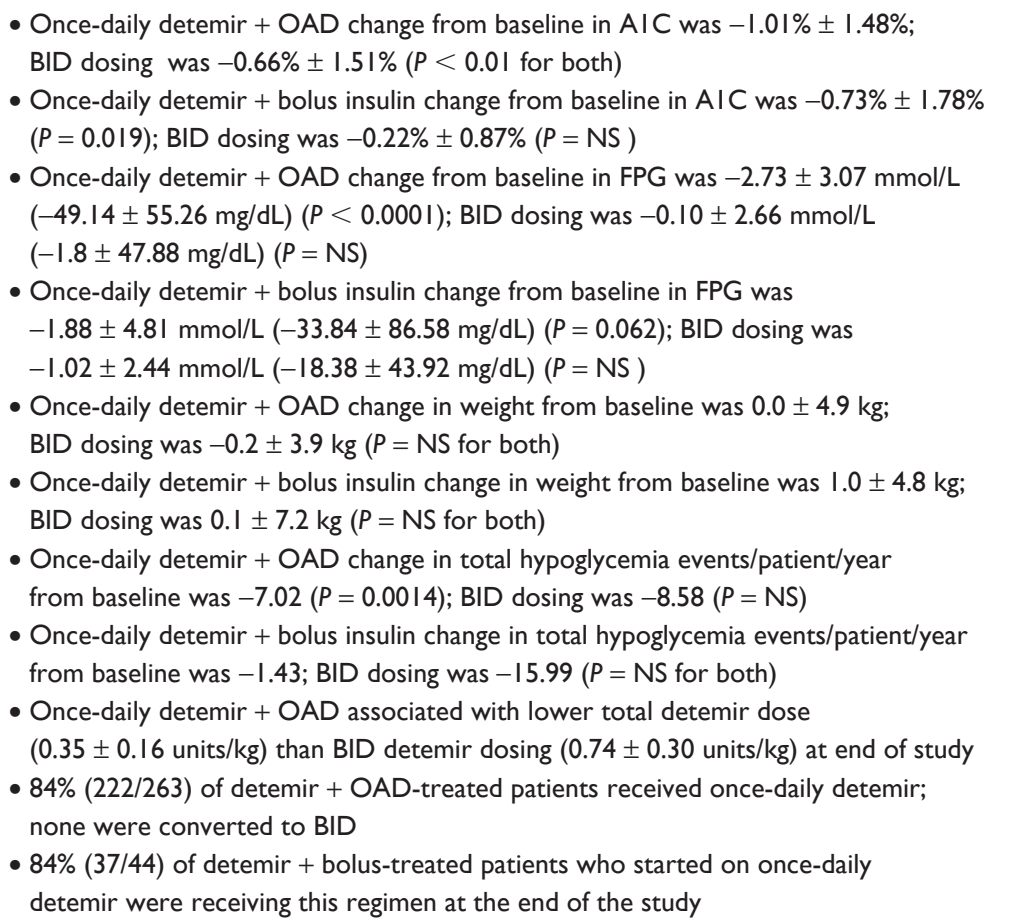 \\
\hline German $^{34}$ & $\begin{array}{l}N=1832 \\
3 \text { months } \\
\text { Transferred to detemir } \pm \text { OAD } \\
\text { from an OAD-only }(n=132 I) \\
N P H \pm \text { OAD }(n=25 I) \\
\text { or glargine } \pm \text { OAD }(n=260)\end{array}$ & $\begin{array}{l}\text { - Change in AIC from baseline for switch from OAD-only was }-1.29 \% \pm 0.03 \% \text {, for } \\
\mathrm{NPH} \pm \text { OAD was }-0.60 \% \pm 0.09 \% \text {, and for glargine was }-0.59 \% \pm 0.06 \%(P<0.000 \mathrm{I} \text { for all }) \\
\text { - Change in FPG for OAD-only was }-3.22 \pm 0.67 \mathrm{mmol} / \mathrm{L}(-58.1 \pm \mathrm{I} .2 \mathrm{mg} / \mathrm{dL}) \text {, for } \\
\mathrm{NPH} \pm \text { OAD was }-\mathrm{I} .62 \pm 0.18 \mathrm{mmol} / \mathrm{L}(-29.1 \pm 3.2 \mathrm{mg} / \mathrm{dL}) \text {, and for glargine } \pm \text { OAD } \\
\text { was }-\mathrm{I} .37 \pm 0.16 \mathrm{mmol} / \mathrm{L}(-24.6 \pm 2.8 \mathrm{mg} / \mathrm{dL})(P<0.000 \mathrm{I} \text { for all }) \\
\text { - Change in weight for OAD-only was }-0.9 \pm 0.1 \mathrm{~kg} \text {, for } \mathrm{NPH} \pm \text { OAD was }-0.9 \pm 0.3 \mathrm{~kg} \text {, } \\
\text { and for glargine } \pm \text { OAD was }-0.8 \pm 0.2 \mathrm{~kg}(P<0.0 \mathrm{I} \text { for all }) \\
\text { - Change in total hypoglycemic events } / \text { patient/year was }-2.7(P<0.000 \mathrm{I}) \\
\text { - Once-daily detemir was used in } 79 \% \text { of patients }\end{array}$ \\
\hline Danish $^{35}$ & $\begin{array}{l}\mathrm{N}=77 \\
3 \text { months } \\
\text { Detemir + bolus insulin }\end{array}$ & $\begin{array}{l}\text { - Change in AIC from baseline was }-0.3 \% \pm 1.1 \%(P=\mathrm{NS}) \\
\text { - Change in FPG was }-2.7 \pm 3.9 \mathrm{mmol} / \mathrm{L}(48.6 \pm 70.2 \mathrm{mg} / \mathrm{dL})(P=\mathrm{NS}) \\
\text { - Change in weight was }-1.0 \mathrm{~kg}(P=0.04) \\
\text { - Mean change in the incidence of total hypoglycemic episodes was }-17.7 \\
\text { episodes/patient/year }(P=0.00 \mathrm{I} 2) \\
\text { - Detemir used once daily in } 49 \% \text { and twice daily in } 34 \% \text { of patients; data } \\
\text { were missing for remaining patients }\end{array}$ \\
\hline European $^{36}$ & $\begin{array}{l}\mathrm{N}=2377 \\
\text { I4.4 weeks } \\
\text { Detemir } \pm \text { OADs, } \\
\text { insulin-naive }\end{array}$ & $\begin{array}{l}\text { - Change in AIC from baseline was }-1.3 \pm \mathrm{I} .3 \%(P<0.000 \mathrm{I}) \\
\text { - Change in FPG/FBG } \text { was }-3.7 \pm 3.3 \mathrm{mmol} / \mathrm{L}(-66.6 \pm 59.4 \mathrm{mg} / \mathrm{dL})(P<0.000 \mathrm{I}) \\
\text { - Within-subject FPG/FBG variability was }-0.5 \pm \mathrm{I} .2 \mathrm{mmol} / \mathrm{L}(-9.0 \pm 2 \mathrm{I} .6 \mathrm{mg} / \mathrm{dL})(P<0.000 \mathrm{I}) \\
\text { - Change in body weight was }-0.7 \pm 3.5 \mathrm{~kg}(P<0.000 \mathrm{I}) \text {; reductions in body weight most } \\
\text { apparent in patients with a higher baseline } \mathrm{BMI} \\
\text { - I } 3 \% \text { of patients reported weight loss of }>3 \mathrm{~kg} \text { at the end of study } \\
\text { - Change in mean number of hypoglycemic episodes per patient year was }-0.3(P=0.27) \\
\text { - Mean daily dose of detemir was } 22 \text { units } \\
\text { - Detemir used once daily in } 82 \% \text { of patients }\end{array}$ \\
\hline
\end{tabular}

Note: a Fasting blood glucose or fasting plasma glucose, depending on glucose meter used.

Abbreviations: AIC, glycosylated hemoglobin $\mathrm{A}_{I c}$; BID, twice daily; BMI, body mass index; FBG, fasting blood glucose; FPG, fasting Plasma glucose; NS, not significant; OAD, oral antidiabetes drug; PREDICTIVE, Predictable Results and Experience in Diabetes through Intensification and Control to Target: an International Variability Evaluation.

be more effective at adjusting the insulin regimen than standard-of-care practices. Hypoglycemia rates decreased significantly from baseline to end of study, from 9.05 to 6.44 events/patient/year for the 303 algorithm group
$(P<0.0039)$ and from 9.53 to 4.95 for the standard-ofcare group $(P<0.0001)]$. Results from PREDICTIVE 303 indicate that self-adjusted dosing and once-daily dosing of detemir is effective. 
A post hoc subgroup analysis that evaluated insulinnaive patients in the PREDICTIVE 303 study found that by study end, $95 \%$ of patients in the 303 algorithm group remained on once-daily detemir and were able to effectively implement the 303 algorithm to achieve improvements in glycemic control. ${ }^{26}$ These results are consistent with the findings from the observational PREDICTIVE study conducted in Europe.

Two additional subgroup analyses of European cohorts of PREDICTIVE were conducted and suggested that switching to once-daily detemir from NPH or glargine therapy is associated with significantly improved glycemic control. In a cohort of 777 patients with T2DM, Yenigun and Honka found that switching from once or twice-daily glargine to once-daily detemir was associated with a significant reduction in A $1 \mathrm{C}$ from baseline $(0.51 \%$ and $0.89 \%$, respectively; $P<0.05$ for both groups). ${ }^{37}$ The mean reduction in FPG was significant in the once-daily and twice-daily to oncedaily transition groups $(1.63 \pm 2.42[29.3 \pm 43.56]$ and $1.91 \pm 2.35[34.4 \pm 42.3] \mathrm{mmol} / \mathrm{L}[\mathrm{mg} / \mathrm{dL}]$, respectively; $P<0.05$ ). The mean reduction in body weight from baseline was significant in the once-daily to once-daily transition group $(0.3 \pm 3.2 \mathrm{~kg} ; P<0.05)$ but not in the twice-daily to once-daily transition group $(0.3 \pm 1.7 \mathrm{~kg} ; P=\mathrm{NS})$. Similar results were observed by Sreenan et al, when transitioning from NPH to once-daily detemir. ${ }^{38}$ A cohort of 2137 patients with T2DM was evaluated. The mean reduction in A1C was $0.56 \%$ for both groups $(P<0.001$ from baseline for both) transitioning from once or twice-daily NPH. The mean change from baseline in FPG was significantly reduced when patients transitioned from NPH to detemir (1.63 [29.34] and 1.91 [34.38] mmol/L [mg/dL] for the once-daily to once-daily and the twice-daily to once-daily transition groups, respectively; $P<0.05$ for both groups). Switching to once-daily detemir from once-daily NPH decreased the overall rate of hypoglycemic events by 10.2 episodes/patient year $(P<0.001)$ and from twice-daily NPH it decreased the rate by $11.3(P<0.001)$. The daily dose of detemir at the end of study was 8.1 units less per day than the prestudy NPH twice-daily dose, and was 4 units higher than the prestudy NPH once-daily dose.

The significant reduction in weight observed with detemir in comparison to NPH in clinical studies has not been explained by differences in the incidence of hypoglycemia or dose,$^{39}$ and the mechanisms underlying the positive weight effects of detemir compared with NPH or glargine are currently unknown. Hypotheses include that insulin detemir may affect satiety signaling and energy homeostasis or that detemir's albumin-binding properties may allow a greater exposure of detemir to the liver and less to peripheral adipose tissue, which could limit adipogenesis. ${ }^{40,41}$ However, these findings have not been confirmed and the proposed mechanisms are so speculative and so varied in nature that researchers are unsure as to which direction to follow to further elucidate the question.

Questions regarding the association of long-acting insulin analogs and induction of cancer have been investigated. According to a 2010 consensus statement issued by the ADA and the American Cancer Society (ACS), ${ }^{42}$ cancer and diabetes are diagnosed within the same individual more frequently than would be expected by chance, even after adjusting for age. The statement notes that, according to preliminary evidence, an association exists between exogenous insulin and increased cancer risk, and identifies a series of "widely publicized" epidemiologic analyses that examined a potential association between cancer and insulin use and/or use of the long-acting insulin analog glargine. The statement acknowledges the likelihood that confounding by unmeasured or incompletely measured risk factors may explain at least in part the reported associations between insulin and increased cancer risk, and describes a 5 -year trial ${ }^{43}$ of glargine vs NPH $(n=1017)$ that did not find evidence of excess cancer risk with glargine, although the number of cancer endpoints (57 glargine, $62 \mathrm{NPH}$ ), the statement notes, was small. The ADA/ACS statement ultimately recommends that cancer risk should not be a major factor in choosing between available diabetes therapies for the average patient. A meta-analysis by Dejgaard et al, ${ }^{44}$ not cited in the position statement, evaluated data from 8693 patients with type 1 or type 2 diabetes enrolled in randomized and controlled diabetes trials of at least 12 weeks in duration that compared detemir with NPH or glargine. The estimated OR for a cancer diagnosis between NPH and detemir was statistically significant and favored detemir. There was a more than twofold higher cancer occurrence in the NPH-treated population compared with detemir and a similar occurrence of a cancer diagnosis compared with glargine.

\section{Holistic approach to T2DM management}

Evidence supports a holistic approach to diabetes management using multidisciplinary teams that include a diabetes 
specialist nurse, psychologist, nutritionist, and pharmacist to best address the complex medical care of patients with T2DM. ${ }^{45}$ The Global Partnership for Effective Diabetes Management is a multidisciplinary group of international diabetes experts that strives to provide guidance and support for diabetes management teams to help more patients achieve treatment goals. The group is focused on increasing awareness of current treatment guidelines and encouraging implementation of these guidelines in the clinical practice setting. A holistic approach is one of the 10 key practical recommendations of the Global Partnership for Effective Diabetes Management. In addition to controlling hyperglycemia, therapies directed at controlling other coexisting conditions of T2DM, such as dyslipidemia, hypertension, and obesity, may decrease the risk of developing microvascular and cardiovascular complications. ${ }^{2}$ Selecting therapies that minimize weight gain may help to reduce the barriers that prevent patients with T2DM from initiating or complying with insulin therapy (described in detail in a 2009 review by FX Pi-Sunyer) ${ }^{46}$ and support a holistic approach to treatment. Multidisciplinary group members should encourage structured patient education and self-care so responsibility for achieving agreed glucose and comorbid condition treatment goals is shared..$^{45}$

\section{Conclusion}

Protocols for some earlier clinical studies of detemir evaluated twice-daily dosing of detemir; this may have influenced clinical practice and clinician perception that detemir should be prescribed this way for all patients. However, detemir is FDA-approved for once-daily dosing in patients with T2DM or T1DM. ${ }^{14}$ The efficacy, safety, and feasibility of once-daily dosing of detemir are supported by glucose clamp study data and clinical trials..$^{16,25,27-29}$ Results from the European cohorts of the observational PREDICTIVE study indicate that once-daily detemir is more commonly used in clinical practice than twice-daily dosing. ${ }^{34,36,47,48}$ In addition, once-daily detemir is as effective as twice-daily dosing in providing glycemic control and generally requires the use of less detemir insulin. ${ }^{25,33}$ Data show that once-daily detemir controls A1C and is associated with no weight gain or less weight gain than comparator regimens. Weight gain could make it more difficult to achieve glycemic control and exacerbate preexisting cardiovascular risk factors. Involvement of a multidisciplinary team and using a holistic approach for the treatment of T2DM patients are recommended to achieve and maintain the best patient outcomes. Adding a prandial insulin to the regimen before considering detemir twice daily may provide better glycemic control for patients who have not achieved glycemic control with a basal dose of once-daily detemir.

\section{Acknowledgments}

The author would like to thank Beatriz Manzor Mitrzyk, PharmD, of MedVal Scientific Information Services, LLC, for providing writing and editorial assistance. This manuscript was prepared according to the International Society for Medical Publication Professionals' Good Publication Practice for Communicating Company-Sponsored Medical Research: the GPP2 Guidelines. Funding to support the preparation of this manuscript was provided by Novo Nordisk Inc.

\section{Disclosure}

The author has no potential conflicts of interest to report in relation to this paper.

\section{References}

1. Nathan DM, Buse JB, Davidson MB, et al. Medical management of hyperglycemia in type 2 diabetes: a consensus algorithm for the initiation and adjustment of therapy. A consensus statement of the American Diabetes Association and the European Association for the Study of Diabetes. Diabetes Care. 2009;32:193-203.

2. American Diabetes Association. Standards of medical care in diabetes 2011. Diabetes Care. 2011;34(Suppl 1):S11-S61.

3. Humulin ${ }^{\mathbb{B}} \mathrm{N}$ (NPH human insulin [rDNA origin]) [prescribing information]. Indianapolis, IN: Eli Lilly and Company; 2009.

4. Raslova K. An update on the treatment of type 1 and type 2 diabetes mellitus: focus on insulin detemir, a long-acting human insulin analog. Vasc Health Risk Manag. 2010;6:399-410.

5. Hartman I. Insulin analogs: impact on treatment success, satisfaction, quality of life, and adherence. Clin Med Res. 2008;6:54-67.

6. Lantus ${ }^{\circledR}$ (insulin glargine [rDNA origin] injection) [prescribing information]. Bridgewater, NJ: Sanofi-Aventis US; 2010.

7. Luzio SD, Beck P, Owens DR. Comparison of the subcutaneous absorption of insulin glargine (Lantus ${ }^{\circledR}$ ) and NPH insulin in patients with type 2 diabetes. Horm Metab Res. 2003;35:434-438.

8. Ashwell SG, Gebbie J, Home PD. Twice-daily compared with oncedaily insulin glargine in people with Type 1 diabetes using meal-time insulin aspart. Diabet Med. 2006;23:879-886.

9. Garg SK, Gottlieb PA, Hisatomi ME, et al. Improved glycemic control without an increase in severe hypoglycemic episodes in intensively treated patients with type 1 diabetes receiving morning, evening, or split dose insulin glargine. Diabetes Res Clin Pract. 2004;66:49-56.

10. Albright ES, Desmond R, Bell DS. Efficacy of conversion from bedtime NPH insulin injection to once- or twice-daily injections of insulin glargine in type 1 diabetic patients using basal/bolus therapy. Diabetes Care. 2004;27:632-633.

11. Devries JH, Nattrass M, Pieber TR. Refining basal insulin therapy: what have we learned in the age of analogues? Diabetes Metab Res Rev. 2007;23:441-454.

12. Whittingham JL, Havelund S, Jonassen I. Crystal structure of a prolonged-acting insulin with albumin-binding properties. Biochemistry. 1997;36:2826-2831. 
13. Kurtzhals P, Havelund S, Jonassen I, Kiehr B, Ribel U, Markussen J. Albumin binding and time action of acylated insulins in various species. J Pharm Sci. 1996;85:304-308.

14. Levemir ${ }^{\circledR}$ (insulin detemir [rDNA origin] injection) [prescribing information]. Princeton, NJ: Novo Nordisk Inc; 2009.

15. Chapman TM, Perry CM. Insulin detemir: a review of its use in the management of type 1 and 2 diabetes mellitus. Drugs. 2004;64: $2577-2595$.

16. Klein O, Lynge J, Endahl L, Damholt B, Nosek L, Heise T. Albuminbound basal insulin analogues (insulin detemir and NN344): comparable time-action profiles but less variability than insulin glargine in type 2 diabetes. Diabetes Obes Metab. 2007;9:290-299.

17. King AB. Once-daily insulin detemir is comparable to once-daily insulin glargine in providing glycaemic control over $24 \mathrm{~h}$ in patients with type 2 diabetes: a double-blind, randomized, crossover study. Diabetes Obes Metab. 2009;11:69-71.

18. Bott S, Tusek C, Jacobsen LV, et al. Insulin detemir under steady-state conditions: no accumulation and constant metabolic effect over time with twice daily administration in subjects with type 1 diabetes. Diabet Med. 2006;23:522-528.

19. Hermansen K, Davies M, Derezinski T, Ravn GM, Clauson P, Home P. A 26-week, randomized, parallel, treat-to-target trial comparing insulin detemir with NPH insulin as add-on therapy to oral glucose-lowering drugs in insulin-naive people with type 2 diabetes. Diabetes Care. 2006;29:1269-1274.

20. Haak T, Tiengo A, Draeger E, Suntum M, Waldhausl W. Lower within-subject variability of fasting blood glucose and reduced weight gain with insulin detemir compared to NPH insulin in patients with type 2 diabetes. Diabetes Obes Metab. 2005;7: $56-64$.

21. Rosenstock J, Davies M, Home PD, Larsen J, Koenen C, Schernthaner G. A randomised, 52-week, treat-to-target trial comparing insulin detemir with insulin glargine when administered as add-on to glucose-lowering drugs in insulin-naive people with type 2 diabetes. Diabetologia. 2008;51:408-416.

22. Hollander P, Cooper J, Bregnhoj J, Pedersen CB. A 52-week, multinational, open-label, parallel-group, noninferiority, treat-to-target trial comparing insulin detemir with insulin glargine in a basal-bolus regimen with mealtime insulin aspart in patients with type 2 diabetes. Clin Ther. 2008;30:1976-1987.

23. Raskin P, Gylvin T, Weng W, Chaykin L. Comparison of insulin detemir and insulin glargine using a basal-bolus regimen in a randomized, controlled clinical study in patients with type 2 diabetes. Diabetes Metab Res Rev. 2009;25:542-548.

24. Raslova K, Bogoev M, Raz I, Leth G, Gall MA, Hancu N. Insulin detemir and insulin aspart: a promising basal-bolus regimen for type 2 diabetes. Diabetes Res Clin Pract. 2004;66:193-201.

25. Meneghini L, Koenen C, Weng W, Selam JL. The usage of a simplified self-titration dosing guideline (303 Algorithm) for insulin detemir in patients with type 2 diabetes-results of the randomized, controlled PREDICTIVE 303 study. Diabetes Obes Metab. 2007;9: 902-913.

26. Selam JL, Koenen C, Weng W, Meneghini L. Improving glycemic control with insulin detemir using the 303 Algorithm in insulin naive patients with type 2 diabetes: a subgroup analysis of the US PREDICTIVE 303 study. Curr Med Res Opin. 2008;24:11-20.

27. Fajardo Montanana C, Hernandez Herrero C, Rivas Fernandez M. Less weight gain and hypoglycaemia with once-daily insulin detemir than NPH insulin in intensification of insulin therapy in overweight type 2 diabetes patients - the PREDICTIVETM BMI clinical trial. Diabet Med. 2008;25:916-923.

28. Philis-Tsimikas A, Charpentier G, Clauson P, Martinez Ravn G, Roberts VL, Thorsteinsson B. Comparison of once-daily insulin detemir with NPH insulin added to a regimen of oral antidiabetic drugs in poorly controlled type 2 diabetes. Clin Ther. 2006;28: $1569-1581$.
29. Blonde L, Merilainen M, Karwe V, Raskin P. Patient-directed titration for achieving glycaemic goals using a once-daily basal insulin analogue: an assessment of two different fasting plasma glucose targets - the TITRATE study. Diabetes Obes Metab. 2009;11:623-631.

30. Holman RR, Farmer AJ, Davies MJ, et al. Three-year efficacy of complex insulin regimens in type 2 diabetes. $N$ Engl J Med. 2009;361: $1736-1747$.

31. Holman RR, Thorne KI, Farmer AJ, et al. Addition of biphasic, prandial, or basal insulin to oral therapy in type 2 diabetes. $N$ Engl $\mathrm{J}$ Med. 2007;357:1716-1730.

32. Luddeke HJ, Sreenan S, Aczel S, et al. PREDICTIVE - a global, prospective observational study to evaluate insulin detemir treatment in types 1 and 2 diabetes: baseline characteristics and predictors of hypoglycaemia from the European cohort. Diabetes Obes Metab. 2007;9:428-434.

33. Fontaine P, Gin H, Pinget M, et al. Effect of insulin detemir dose frequency on clinical outcomes in patients with diabetes in PREDICTIVE. Adv Ther. 2009;26:535-551.

34. Meneghini LF, Rosenberg KH, Koenen C, Merilainen MJ, Luddeke HJ. Insulin detemir improves glycaemic control with less hypoglycaemia and no weight gain in patients with type 2 diabetes who were insulin naive or treated with NPH or insulin glargine: clinical practice experience from a German subgroup of the PREDICTIVE study. Diabetes Obes Metab. 2007;9:418-427.

35. Hermansen K, Lund P, Clemmensen K, et al. 3-month results from Denmark within the globally prospective and observational study to evaluate insulin detemir treatment in type 1 and type 2 diabetes: the PREDICTIVE study. Rev Diabet Studies. 2007;4:89-97.

36. Dornhorst A, Luddeke HJ, Sreenan S, et al. Insulin detemir improves glycaemic control without weight gain in insulin-naive patients with type 2 diabetes: subgroup analysis from the PREDICTIVE study. Int J Clin Pract. 2008;62:659-665.

37. Yenigun M, Honka M. Switching patients from insulin glargine-based basal-bolus regimens to a once daily insulin detemir-based basal-bolus regimen: results from a subgroup of the PREDICTIVE study. Int J Clin Pract. 2009;63:425-432.

38. Sreenan S, Virkamaki A, Zhang K, Hansen JB; PREDICTIVE study group. Switching from NPH insulin to once-daily insulin detemir in basal-bolus-treated patients with diabetes mellitus: data from the European cohort of the PREDICTIVE study. Int J Clin Pract. 2008;62: 1971-1980.

39. Davies MJ, Derezinski T, Pedersen CB, Clauson P. Reduced weight gain with insulin detemir compared to NPH insulin is not explained by a reduction in hypoglycemia. Diabetes Technol Ther. 2008;10:273-277.

40. Lau DC. Diabetes and weight management. Prim Care Diabetes. 2010; 4(Suppl 1):S24-S30.

41. Hordern SVM, Wright JE, Umpleby AM, Shojaee-Moradie F, Amiss J, Russell-Jones DL. Comparison of the effects on glucose and lipid metabolism of equipotent doses of insulin detemir and NPH insulin with a 16-h euglycaemic clamp. Diabetologia. 2005;48:420-426.

42. Giovannucci E, Harlan DM, Archer MC, et al. Diabetes and cancer: a consensus report. Diabetes Care. 2010;33:1674-1685.

43. Rosenstock J, Fonseca V, McGill JB, et al. Similar risk of malignancy with insulin glargine and neutral protamine Hagedorn (NPH) insulin in patients with type 2 diabetes: findings from a 5-year randomised, open-label study. Diabetologia. 2009;52:1971-1973.

44. Dejgaard A, Lynggaard H, Rastam J, Krogsgaard TM. No evidence of increased risk of malignancies in patients with diabetes treated with insulin detemir: a meta-analysis. Diabetologia. 2009;52:2507-2512.

45. McGill M, Felton AM. New global recommendations: a multidisciplinary approach to improving outcomes in diabetes. Prim Care Diabetes. 2007; 1:49-55.

46. Pi-Sunyer FX. The impact of weight gain on motivation, compliance, and metabolic control in patients with type 2 diabetes mellitus. Postgrad Med. 2009;121:94-107. 
47. Dornhorst A, Luddeke HJ, Koenen C, et al. Transferring to insulin detemir from NPH insulin or insulin glargine in type 2 diabetes patients on basal-only therapy with oral antidiabetic drugs improves glycaemic control and reduces weight gain and risk of hypoglycaemia: 14-week follow-up data from PREDICTIVE. Diabetes Obes Metab. 2008; 10:75-81.
48. Dornhorst A, Luddeke HJ, Sreenan S, et al. Safety and efficacy of insulin detemir in clinical practice: 14-week follow-up data from type 1 and type 2 diabetes patients in the PREDICTIVE European cohort. Int J Clin Pract. 2007;61:523-528.

\section{Publish your work in this journal}

Clinical Pharmacology: Advances and Applications is an international, peer-reviewed, open access journal publishing original research, reports, reviews and commentaries on all areas of drug experience in humans The manuscript management system is completely online and includes a very quick and fair peer-review system, which is all easy to use.
Visit http://www.dovepress.com/testimonials.php to read real quotes from published authors. 